EDITORIAL

Rev Chil Salud Pública 2019,

Vol 23(1): 5-7

\title{
BANAL SERÍA NO HABLAR DEL CLIMA
}

\author{
IT WOULD BE BANAL NOT TO TALK ABOUT THE CLIMATE
}

El 2 de septiembre recién pasado el Rector de la Universidad de Chile ha suscrito la carta del clima (Global Climate Emergency Letter) como parte del trabajo del Acuerdo de instituciones de educación por los objetivos de Desarrollo Sustentable (The SDG Accord, 2019) ${ }^{1}$.

Esta carta declara la existencia de una emergencia climática y compromete a sus firmantes a trabajar en tres áreas:

1. Orientar la investigación hacia la acción en cambio climático

2. Ser carbonos neutrales el 2030 o el 2050 a más tardar

3. Reorientar el curriculum y las actividades de extensión hacia la sustentabilidad ambiental

Desde el punto de vista de salud hay tres áreas en que estas metas se nos vuelven urgentes:

1. Fortalecer los trabajos que relevan las implicancias de la emergencia climática en salud. Desde los años 90 existe una notable investigación en las transformaciones de las enfermedades transmisibles, asociadas a vectores, por la emergencia climática (incremento de temperatura media que suman además oscilaciones extremas y pluviosidad concentrada), así como las consecuencias de las no transmisibles ${ }^{2}$. También hay proyecciones sobre los efectos nutricionales del cambio y del incremento del nivel de los mares. Desde el 2015 Lancet ha establecido un observatorio de indicadores, con la inquietud de que las transformaciones climáticas podrían amenazar los logros de los últimos 50 años en salud ${ }^{3}$.

Pero es importante considerar que muchos de los efectos sobre la salud ocurren por otros efectos planetarios más allá del incremento de temperatura media. La contaminación del aire, los suelos, las aguas, la composición industrial de nuestra dieta, son importantes generadores de patología crónica ${ }^{4}$. La megasequía que vive nuestra

Yuri Carvajal B. Editor Asociado Revista Chilena de Salud Pública ycarvajal@med.uchile.cl zona central no es sólo un problema de temperaturas. Ni es la industria extractiva, en el caso chileno la minería, la única responsable. Es el momento de repensar cada una de las cadenas productivas incluyendo las de salud. Y considerando que la agricultura es responsable alrededor de un 30\% de las emisiones de $\mathrm{CO} 2$, de buscar una convergencia entre dieta saludable y alimentación sustentable, derribando nuestros propios mitos carnívoros ${ }^{5}$.

2. En un plano situado, debemos considerar los desafíos de la medicina actual como práctica sustentable. Estimaciones de la huella de carbono de nuestros hospitales señalan que hay mucho trabajo por hacer ${ }^{6}$. Además, en la misma tradición occidental de salud pública, hay desde sus orígenes una apuesta por un conocimiento localizado ${ }^{7}$. Ese mensaje hoy puede tomar un profundo sentido para trabajar en problemas territorializados, con contaminantes varios e industrias múltiples, con 
causas y efectos mal especificados, condenados en la infortunada sentencia de zonas de sacrificio ${ }^{8,9}$.

Estas dimensiones globales y locales a la vez, pueden amalgamarse en el encuentro entre Antropoceno ${ }^{10}$ y zonas críticas ${ }^{11}$. La expresión Antropoceno nos invita a considerar la transformación planetaria abordando el sistema tierra como un entrelazamiento de múltiples ciclos de lo inorgánico con lo vivo. La emergencia climática expresa la gravedad del proceso asociado al carbono, y su condición severamente alterada ${ }^{12}$, pero también otros ciclos, como fósforo y nitrógeno están en situación altamente perturbada. Están además los efectos asociados a una grave reducción de la biodiversidad, trastornos severos en los océanos, contaminación química, uso de suelos, reducción del agua disponible ${ }^{13}$.

3. Todos estos análisis y publicaciones, así como la propia reflexión desde la salud colectiva, deben activarnos hoy en lo inmediato, para una participación presencial en la COP25 junto a la ciudadanía.

Podemos ser actores en al menos cuatro cuestiones apremiantes.

1. Sin duda, la reducción de las emisiones de carbono es la primera tarea. Nuestras modestas instituciones, nuestra humilde vida personal, deben ser carbono neutral el 2030. Es el primer paso para poder exigir que las organizaciones más soberbias se tornen carbono neutrales el 2040. Chile debe tener un plan para el cierre de sus termoeléctricas. El plazo para aquellas que tienen más de 40 años se ha cumplido.

2. Chile es una larga herida ambiental. Donde ponemos un dedo, hay un malestar, signos y síntomas. Nuestros ríos y mares expresan la afectación del ciclo hidrológico, los cerros cultivados hasta sus cumbres, los helechos resecos de la quebradas ayer húmedas, las alstroemerias en regresión, los culpeos buscando alguna fruta de los senderistas de los parques, los pilpilenes anidando junto a los letreros que prohíben bañarse en Ventanas. Residuos, termoeléctricas, relaves, fundiciones, plantaciones, salmonicultura. Donemos un porcentaje significativo de nuestro intelecto práctico a dialogar con las comunidades, a estudiar los problemas y producir visiones comunes, a participar en soluciones.

3. Nuestra práctica profesional debe ser un ejemplo de reciclaje, de bajas emisiones, de sustentabilidad. También la medicina y en particular los hospitales, deben saber cruzar un oceáno de manera no contaminante.

4. Finalmente, somos todos modestos artesanos de las ideas. Reanimemos la fertilidad biológica de nuestros saberes científicos básicos. Hay allí conocimientos primordiales, que contienen claves para un diálogo entre pares con los pueblos originarios y sus saberes ${ }^{14}$.

Si el próximo año se cumplen 500 años del encuentro de Chile con occidente (cruce del estrecho de Magallanes), un fecundo trabajo intelectual puede servir para que en esta COP25 iniciemos una ingeniería reversa de algunas ideas perturbadoras que nos han conquistado. 


\section{REFERENCIAS BIBLIOGRÁFICAS}

1. The SDG Accord. Universities and Colleges for the Climate Summit; 2019.

2. Bozinovic F, Cavieres L. La vulnerabilidad de los organismos al cambio climático: rol de la fisiología y la adaptación. Santiago: Pontificia Universidad Católica de Chile. Facultad de Ciencias Biológicas. Center of Applied Ecology and Sustainabilty (CAPES) y Universidad de Concepción Facultad de Ciencias Naturales y Oceanógráficas. Instituto de Ecología y Biodiversidad (IEB); 2019.

3. Watts N, Amann M, Ayeb-Karlsson S, Belesova K, Bouley T, Boykoff M, et al. The Lancet Countdown on health and climate change: from 25 years of inaction to a global transformation for public health. Lancet. 2018;p. 581-630.

4. Landrigan P, Fuller R, Acosta N, Adeyi O, Arnold R, Basu N, et al. The Lancet Commission on pollution and health. Lancet. 2017;p. 462-512.

5. Willett W, Johan Rockström BL, Springmann M, Lang T, Vermeulen S, Garnett T, et al. Food in the Anthropocene: the EAT-Lancet Commission on healthy diets from sustainable food systems. Lancet. 201919 January;6736(18):31788.
6. Balkenhol M, Castillo A, Soto M, Feijoo M, Merino W. Huella de Carbono en el Hospital Base de Puerto Montt. Rev Med Chile. 2018;146(10):1384-1389.

7. Hipócrates. Tratados Hipocráticos II. Sobre los aires, aguas y lugares. Madrid: Gredos;1986.

8. Siches I. Editorial. La "cuestión" medioambiental. Vida Médica. 2019 agosto 2019;71(2):4.

9. AAVV. Salud \& Ambiente. geografías en sacrificio. 2019;59(1):1-78. Cuadernos Médico-Sociales.

10. Bonneuil C, Fressoz JB. The Shock of the Anthropocene. London-New York: Verso; 2017.

11. Latour B. ¿Es la geo-logía el nuevo paraguas para todas las ciencias...? Sugerencias para una universidad neo-Humboldtiana. Chamiza: Humus-editores; 2017.

12. Lenton T. EARTH SYSTEM SCIENCE A Very Short Introduction. Oxford: Oxford Univerity Press; 2016.

13. Carvajal Y. Antropoceno. Nuevos folios de Bioética. 2016;(19):23-30. Disponible en http://www.revistas. uchile.cl/index.php/NFB.

14. de Lamarck JB. Filosofía zoológica. Madrid: La Oveja Roja; 2017 [1809]. 